\title{
National Urban System dynamics in priorities of agricultural industry stimulation (the case of Russia)
}

\author{
Denis Ushakov ${ }^{1, *}$ \\ ${ }^{1}$ IC, Suan Sunandha Rajabhat University, 1 U-Thong Nok rd, 10200 Dusit, Bangkok, Thailand
}

\begin{abstract}
Cities' transformation into active actors of international economic relations, their participation in international competition form a complex of relevant problems about efficiency of relationships between business and government, global competitive advantages of urban economies, quality of municipal governance, development and international integration of the urban system of the modern countries (including Russia). Paper examines a development of the modern features of the urban system in Russia, analyzes its macroeconomic indicators, actual problems, and evaluates various scenarios for the development of both individual urban economies and the entire urban system of Russia.
\end{abstract}

\section{Introduction}

Modernization of economy of Russia with world's largest natural resource, personnel, innovation and technological potential should be based on transformation of mechanisms for Russian industries' integration in world globalizing economic space. Improvement of efficiency of Russia's involvement in globalization trends requires an adaptation of the Russian economy to leading global trends - growth of modern cities economic importance and concentration of world economic activity within the boundaries of magapolices' global network.

Features of formation of Russian urban model and national system of Russia' cities' territorial distribution, as well as modern problems of Russian cities' functioning that became particularly acute in conditions of Russia' economic growth slowing, reducing of indigenous population and growth of international migration, identified an importance and relevance of finding modern approaches to urban management systems in Russia and scenarios of Russia further urban environment development.

The purpose of the study is to define, based on the analysis of factors and features of Russia urban economy development, the possible scenarios of Russian urban economic systems progress, as well as the tools to modernize Russian city network for its adaptation to needs of the global economy and world market trends.

Objectives of the study:

- to assess current economic role of cities in the functioning of Russia economic system;

- to identify patterns of economic development of Russia cities during the past 20 years;

*Corresponding author: denis.us@ssru.ac.th 
- to consider the main problems of formation and present stage of Russia urban economy development;

- to clear possible scenarios of Russia urban system progress, to assess abilities of achieving an optimal performance of the Russian system of municipal services in the future;

- to set recommendations for modernization of the Russian urban economy in the short term.

\section{Theoretical and statistical basics of the study}

Russia is a geographically largest country in the world and leading economic system in the structure of global economy. Cities are places for residence and employment of almost 2/3 of Russians. This, on the one hand, allows considering Russia as an urbanized state. On the other hand, evaluation of the sources of Russia's GDP shows diametrically opposite results - a large part of Russia's gross domestic product is not formed in the cities but in rural areas (primarily in the regions of natural resources location).

Russian cities are very different by their population, specialization of urban economic system, and own importance in national economy.

We can analyze an economic performance of Russian cities based on the largest cities classification on two categories - cities with population over 1 million (category A) and cities with population $0.5-1$ million (category B) people (Tab. 1).

Analysis of Russian statistic (Rosstat) data allows determination a share of cities of both categories in fixed assets, number of enterprises, retail trade and direct investments of Russia in 2018.

Fixed assets and number of enterprises of the cities of category B, in general, is proportional to share of these cities in population of Russia.

At the same time, cities of category B have less achievements in spheres of investment and retail (if comparing with cities of category A). It's obvious that most of fixed assets, entrepreneurs, retail sales and investments belong to medium and small towns and countryside of Russian Federation; and confirms that Russia is not a country of urban economies.

Share of megacities (category A) in general population of Russia slightly decreased, while share of second-tier cities significantly increased.

At the same time, the share of cities with a population of $0.5-1$ million in the total number of Russian enterprises significantly increased (more than for 2\%).

The share of large Russian cities in retail trade critically fell. Meanwhile the share of category A cities in retail trade fell in two times (!) to $25 \%$, and share of category B cities fell in three times (to 4.6\%). This statistic data confirms an increasing role of provincial consumer markets in Russia, and is also evidenced by formation of federal retailers, their access to regions, and growth of consumer activity in the village due to implementation of federal and regional programs for countryside supporting.

Leadership of the largest cities in Russia in attracting of local and international investment retained in 2018 (the share of biggest Russian cities in total national investment stream increased for 3\%), while similar index for cities of category B fell to 5,6\%.

Such gap can be explained by relatively high level of development of financial and business infrastructure in metropolitan areas, as well as by fact that majority of largest Russian companies is registered in big cities. In general, such differentiation in the investment flows is typical for most countries, including geographically large ones that have similar socio-economic characteristics with Russia. 
Table 1. Russian cities and their population in 2018, mln (Data of Russian Statistic Bureau).

\begin{tabular}{|c|l|c|c|l|c|}
\hline \multicolumn{2}{|c|}{ Category A (top 5 cities) } & \multicolumn{3}{c|}{ Category B (top 5 cities) } \\
\hline 1 & Moscow & 10563 & 1 & Perm & 986.5 \\
\hline 2 & S - Petersburg & 4600 & 2 & Volgograd & 979.6 \\
\hline 3 & Novosibirsk & 1409 & 3 & Krasnoyarsk & 962.5 \\
\hline 4 & Ekaterinburg & 1343 & 4 & Saratov & 827.2 \\
\hline 5 & Nijny Novgorod & 1271 & 5 & Voronezh & 847.6 \\
\hline & Totally: & 25755 & & Totally: & 15463.5 \\
\hline
\end{tabular}

Famous business magazine "Forbes" also published a ranking of the best Russian cities for business. Experts estimated 103 Russian cities with a population over 150,000 people. Cities are evaluated by 18 indicators of socio-economic development such as: city's stability, social characteristics, business climate, and purchasing power of local population, infrastructure, and convenience of doing business.

First and second places by Forbes rating in 2018 belonged to Krasnodar and Khabarovsk. Another eight positions in Top-10 belonged to Yekaterinburg, Chelyabinsk, Novosibirsk, Omsk, Rostov-on-Don, Samara, Sochi, and Krasnoyarsk. First time Sochi got a ninth rank in top-10.

Table 2. Business environment of Russian cities, ranking, 2018 (Rosstat, 2018).

\begin{tabular}{|c|c|c|c|c|c|}
\hline \multicolumn{6}{|c|}{ Russian cities with population: } \\
\hline \multicolumn{2}{|r|}{ Over $1 \mathrm{mln}$} & \multicolumn{2}{|r|}{$0,5-1 \mathrm{mln}$} & \multicolumn{2}{|r|}{ Under $0,5 \mathrm{mln}$} \\
\hline 1 & Yekaterinburg & 1 & Krasnodar & 1 & Surgut \\
\hline 2 & Ufa & 2 & Krasnoyarsk & 2 & Sochi \\
\hline 3 & Kazan & 3 & Tyumen & 3 & Belgorod \\
\hline 4 & Novosibirsk & 4 & Toliatti & 4 & Vologda \\
\hline 5 & Omsk & 5 & Perm & 5 & Stavropol \\
\hline 6 & Rostov-on-Don & 6 & Voronezh & 6 & Tver' \\
\hline 7 & Samara & 7 & Irkutsk & 7 & Sterlitamak \\
\hline 8 & N. Novgorod & 8 & Kemerovo & 8 & Magnitogorsk \\
\hline 9 & Chelyabinsk & 9 & Barnaul & 9 & Kirov \\
\hline 10 & Volgograd & 10 & Khabarovsk & 10 & Chita \\
\hline
\end{tabular}

Development of Russian cities and other municipalities occurs in difficult conditions. Specificity of urban settlements formation (especially in the Soviet era), consequences of extremely swift and painful changes of socio-economic system in Russia affects national urban system's formation and development.

Urban development within a "policy distribution of productive forces", led to formation of at least four problems that Russian cities are facing now:

- narrowness of urban tax base, when municipal (regional) budgets are heavily dependent on a limited number of companies;

- congestion of major cities' tax base, lack of sources to reduce a tax burden due to emergence of new growth points outside of major cities or urban agglomerations (in rural areas);

- urban manufacturing sector's burdened by "costs of scale" such as high communal tariffs, big governmental housing fund, and significant "social costs" (price of maintaining an appropriate level of social infrastructure);

- presence of number of urban settlements that peculiar only to USSR (for example, capitals of national republics, that are initially unable to be large inter-regional economic centers; poorly located city; towns of one-company (mono-towns), that are strictly depending on one main enterprise development). The prospects of these cities' 
development in actual economic conditions are extremely uncertain. Any progressive experience of these cities' management is absent.

The peculiarities of modern budgetary relations redistribute funds not in favor of cities or other municipalities. According to data of Russia Ministry of Regional Development, during last three years a share of subjects of Federation (regions) in consolidated Federal budget of Russia increased for $8 \%$, while the share of municipal budgets decreased for $7 \%$.

A modern trend of sharp reduction of municipal funds allocated for local development becomes particularly dangerous. Today most of municipal budgets in Russia consist only of current expenditures. The share of funds in municipal budgets that are allocated for local development since 1992 in Russia has decreased from 7 to $2.5 \%$. Even in the most affluent cities it fell from 22 to $6 \%$.

Management of urban economy in market conditions is incomparably more difficult than in the Soviet ones. Now city management faces a great number of autonomous organizations and owners, with thousands of countervailing factors with objective character [1].

One of the biggest dangers faced by city authorities in market environment is need to resist a pressure of urban real estate speculators. Russian cities' authorities are poorly armed for this opposition, for fighting against "slumizations" of parts of the cities, with randomization of cities' development and rampant land speculation.

Almost all XX century Russia (USSR) lived in virtual isolation from other world, and is rapidly opening now.

Despite all achievements of Russia globalization, its integration into modern global processes is still relatively low.

According to the index of globalization, published annually in the journal "Foreign Policy" in 2018, Russia got only 47th place (from 62) in the world rank.

Moscow, with 13.5 million populations, is a largest city in the world. But only 10 years ago Russian capital was not even included in a list of global cities (by a version of University of Loughborough, England [2]. After revising this list five years later, in 2004, same group put Moscow on a par with Amsterdam, Boston, Chicago, Madrid, Milan and Toronto [3].

However, this success in field of globalization should not be exaggerated - it refers only to Moscow, and the rest of Russia' urban economic system looks very weak.

Because of own "under-globalizing" economies of Russian cities do not cope with important functions of the major cities in developed countries: spread of innovations and positive results of globalization across the country.

These processes will inevitably be late, and the gap between regions by level and nature of their development will increase.

With increasing of depopulation Russian cities will have to compete for residents. This competition can start even today, but Russian population is immobile due to the costs for transportation and property.

Depopulation will lead to an excess of housing; the cities' authorities will distribute different promises (related with good job, living environment and free education) and subsidies to potential new citizens. A considerable flow of immigrants from abroad certainly will go in the cities country.

Extremely limited opportunities to increase a tax burden in the cities of Russia demanded changes of approaches to urban managing. The solution was found in rejection of old "bureaucratic" urban governance and in transition to more flexible and predictive policy borrowed from business.

Analyzing these changes, David Harvey defined them as a shift of urban policy from managing urban economies without a direct participation to new concept of citymanagement - “entrepreneurial city-management» [4]. 
The main features of entrepreneurial urban management can be summarized in the following points:

Changing the principles of city budget formation; expansion of non-tax revenues by receiving profits from city' participation in business projects and by budget funds directing in the property market (for interests of the urban community).

Public-Private partnerships - the city authorities can support development of local businesses using legal mechanisms and participating in collaborative projects [2]. Local business also can participate in urban development and carrys a share of social responsibility, "earns" money for the city's budget through implementation of various social projects.

Strategy for long-term development. According to entrepreneurial paradigm of city management, a strategy for city development should [5]: 1) be innovative, create competitive advantages of the city, 2) set clear goals and ways to achieve them in the foreseeable future, and 3) not only use entrepreneurial methods discourses and terminology, but to promote themselves on the market, actively form city brand and image.

4. Creation of municipal agencies that can take coordinating and mediating role in project implementation. These agencies work with every project individually and can find individual solutions.

5. Creation and using of expert networks and institutions to "test" urban development projects at various levels (from individual expertise to the international debate).

6. Strong mayor (head of the city) and managerial team, that allows mobilizing resources for urban "enterprise" projects implementation. In this sense, an entrepreneurial city seems like authoritarian-driven, more than democratically-controlled. High risks of errors in authoritarian decision-making process have to be leveled by open public and expert debates, as well as by procedures for different interests' coordination.

7. Favorable business climate. Entrepreneurial cities are not only active business participants, but also create financial and non-financial incentives and benefits, work for investment attractiveness, improve transport and communications infrastructure (that is necessary for effective operation of enterprises and business life of the city), reduce bureaucratic obstacles and administrative barriers. In fact, a social sphere of urban economy starts to work for the growth of business profitability [6].

Thus, the Russian cities are not well-functioning economic systems that are deeply integrated with both a national economy and international production and distribution [7]. Causes of national urban networks fragmentation are internal problems of urban economic systems' functioning (eg, mismatched of most cities' economic structure to modern requirements and standards of international experience, extreme dependence of urban development on interactions with regional and federal authorities, poorly functioning of social infrastructure, etc.) and external conditions (low development of mechanisms of interaction between municipal and Federal authorities, sustained urban development due to political rather than economic reasons).

Currently, the economic system of the Russian cities has low efficiency also due to discrepancy of urban economies to basic principles of cities territorial distribution and existing differentiation of business environment in the cities of Russia [8].

Meanwhile, even in such difficult conditions we can note some progress in implementing of municipal economic policy (for example, city management transition to entrepreneurial principles, growth of municipal investments in city reputation and image), and in organization and structure of urban economy (development of foreign economic relations, partnerships, seeking for additional resources for city development, improving the city competitiveness and investment attractiveness).

These transformations are not only requirements for urban economy effectivization but are also a factor of maintaining the cities as unique socio-economic systems in the difficult 
conditions of present stage of Russia development, under influence of internal and external factors analyzing further.

\section{Results and Discussion: Directions of infrastructural and institutional economic Modernization of Russian cities}

Analyzing scenarios of Russian cities' economic development we have to consider negative / positive effects of two groups of factors - internal (related with urban social-economical systems) and external (features of urban development).

Factors determining development of a modern urban economy of Russia are given in Table 3.

Table 3. Factors of Russia' urban economic systems development in the long-term (made by author).

\begin{tabular}{|c|c|c|}
\hline Groups of factors & Sub-groups of factors & Factors \\
\hline \multirow[t]{8}{*}{ Internal } & \multirow[t]{4}{*}{$\begin{array}{l}\text { Studied } \\
\text { Well forecasted }\end{array}$} & $\begin{array}{l}\text { - threat to lose key economic and geo- } \\
\text { politic positions }\end{array}$ \\
\hline & & - deindustrialization \\
\hline & & - immigration \\
\hline & & - pollution \\
\hline & \multirow[t]{4}{*}{ Poor forecasted } & - population aging; \\
\hline & & - aggressive policy in the real estate market \\
\hline & & - social-economical differentiation \\
\hline & & $\begin{array}{l}\text { increasing of social mobility and } \\
\text { importance of human capital }\end{array}$ \\
\hline \multirow[t]{3}{*}{ External } & Macroeconomic & $\begin{array}{l}\text { - growth of prices for natural resources } \\
\text { - integration in global markets } \\
\text { - legacy of Soviet economy }\end{array}$ \\
\hline & Social - demographic & $\begin{array}{l}\text { - depopulation, population aging } \\
\text { - growth of ethnic migration } \\
\text { - new requirements for the quality and } \\
\text { mobility of human resources }\end{array}$ \\
\hline & $\begin{array}{l}\text { Innovative } \\
\text { technological }\end{array}$ & $\begin{array}{l}\text { - computerization and development of } \\
\text { communication } \\
\text { - cities' turning into conductors of } \\
\text { innovations }\end{array}$ \\
\hline
\end{tabular}

Among internal problems of Russian cities' development we can highlight:

Real threat of loss economic and geopolitical importance of the city. Global trends in the world economy substantially transform relationships between cities. In these conditions urban economies more involved in international relations network, acquire a number of obvious advantages and high competitiveness. At the same time cities, dropping out of the world's economic, political, cultural and other ties move on the periphery of global processes of economic, political and cultural development.

Efficiency of Russia economy, ceteris paribus, increases. But at the same time border between Russia and Kazakhstan and China is laid bare. So we can't be sure that Russia integration into the world economy will not stimulate new problem occurrence. Also we cannot surely forecast situation in neighboring Kazakhstan and rapidly growing China.

Flourishing of Russia, Kazakhstan and China border cities as a result of cross-border cooperation will not save stability. Likelihood of ethnic problems, stimulated by difficulties of ethnic migrants' assimilation in Russian major urban centers is very high. Very high concentration of foreign migrants in the border areas (where migrants are agreeing to live in conditions that are not accepted by Russian urban population) will stimulate replacement of Russian population primarily by Chinese. 
Computerization and development of communications in general leads to a softening of the "burden of Russian distances". But at the same time we can assume that in Russia this effect will be much weaker than in the West. Level of social services, that can be obtained in 10-15 major cities and cannot be informatized or digitized, is not comparable with other area of the country. Hence a conclusion that people involved in the processes of informatization in the foreseeable future will seek to resettle in the major cities.

Another side of transformation processes in the cities is their innovativeness and openness for innovations. Specifics of the current economy require involvement in innovative processes for large part of society. In Russia, the share of this economy is about $10 \%$, while the share of population's employment there is even less.

Cities are multifunctional by their nature and ensure an implementation of multiple social goals. However, in practice, from all variety of urban functions "production" and "consumption" of money has disproportionate importance. Despite this importance, the cities which life philosophy is reduced and limited by these two principles and activities can eventually lose their economic power.

There are many historical examples of sunsets of the cities. For example, rich trade cities that once "paid off" for saving their trade business out of railways; or modern exportoriented industrial centers, that squeeze existing industrial and resources capacities until the last drop [7, 9].

Other dynamics inherent for cities in difficult economic situation, when they are forced to generate changes and quickly find domestic sources of develop. This does not surely mean a prosperity, but cities are moving forward; local people can see prospects; urban processes of gentrification switch on; symbolic capital of the cities mobilizes and cities gradually become more attractive for foreign investment.

Soviet urbanization gave a vivid example of differences between achieved economic growth and poor living conditions. Even if to not look back at the era of Stalinist industrialization, Brezhnev era of rapid urbanization was accompanied by multiple and acute housing and transport problems, by sharp deterioration of environment, man-made disasters, and other social cleavages.

However, social sphere was financed and maintained in that time much better than in previous and subsequent years. It certainly contributed to the accumulation of human capital. This intellectual and professional reserve, despite the catastrophic collapse of economy in early 1990s, allowed quick and successful passing the whole transitional period, also to adapt and to use new technologies, new skills and activities. At the same time, cities with higher level of accumulated human capital passed a transit stage and were included in the process of economic recovery and growth quicker and more successfully.

Previous forms of urban governance mobilization, based on a combination of three basic principles: monopoly - concentration - competition (previously reliably provide an economic growth), now significantly reduce their effectiveness and must be balanced by another triad mobility - coordination - specialization [10].

Mobility suggests that cities' involvement in networking and inter-cities relationships become more important for successful development of urban economy than cities' geographical proximity or administrative subordination. Cities' accessibility now is a key parameter for urban progress.

Movement up by the social lifts is completed by to change a place of residence and to obtaine necessary social services. Mobility and accessibility naturally reduces a level of centralization and helps to equalize the living standards. Cities' coordination involves an information disclosure and reconciliation of interests [11].

Finally, a specialization does not mean increasing of cities' competitive advantages but to achieve a high level of development is priority and socially important area for management in every city. 
Gaining of own image means not only an increasing of autonomy of decision-making process, but also an importance of functions' and responsibilities' redistribution between the Federal and provincial centers and intensifying of services' exchanges.

It is incredibly difficult to implement because Russian cities and provinces still divide spheres of influence. However, various crises Russia's facing now (such as demographic, economic and political) do not leave any chances to live in the previous logic of power and money domination.

The most obvious steps allowing to move from policy of economic growth stimulation to policies of development stimulation and feasible at the municipal government level, are, firstly, support of changes.

Cities need their own sources for innovation to be less dependent on the activities of large corporations. These changes have not only economic but also institutional or organizational nature, affecting the scope of decision-making, management, and building relationships between state and society.

Secondly, formation of unified information space serving any form of intercity exchanges, including the education system, students and professors, providing monitoring of the labor market and real estate, transportation, and cultural ties.

Thirdly, co-usage and co-service of unique and expensive infrastructure, rationalization of necessy infrastructure costs and existing system of health and social welfare in accordance with the structure of the population and its real needs.

Fourthly, sustaining and increasing of capital of diversity that includes not only local features but also possibility of international culture and lifestyle allowing start up of gentrification processes.

Fifthly, environmental problems that are closely connected with improvement of people's health, duration and quality of life.

Finally, a rejection of authoritarian approaches to management in favor of cooperation and more flexible system of decision-making (based on the interests of different groups represented by actors or institutions who share common goals but have different competencies and are not subjects for urban governance).

Thus, in the modern conditions internal characteristic of the cities' economic systems, as well as external characteristics determined by development of the national economy and social trends and factors identify prospects of Russian cities' development, urban system formation, and Russian cities integration into the world economy, as well as the structure of the national economy of Russia [12].

Probability of scenarios for Russian urban economic systems development will depend primarily on the effectiveness of consolidation of municipal government, local business and local community to overcome social inertia in the context of slow economic growth. The solution of many urban problems is largely not related only with additional financing or technical support, but also with overcoming a social resistance to change and Russian federal government approach to solve the problems of urban development.

\section{Solutions and Recommendations}

Cities of Russia concentrate almost two thirds of the population of the country. However, the most of Russian gross domestic product is generated outside the cities but in the regions with natural resources.

The current dynamics of Russian cities development is experiencing a negative impact of historical features of their formation (structure of the Russian urban economy not biased in favor of the "traditionally urban" finance, trade, service, but in favor of mining and manufacturing industries; municipal budgets' dependence on a limited number of local enterprises; high social burden on the municipal budgets; and the lack of opportunities to 
reduce tax burden by emerging of new growth points outside of major cities or urban agglomerations) and consequences of extremely painful change of socio- economic structures in Russia in $1990^{\text {th }}[13,14]$.

The system of Russian cities is low effective also due its inconsistency to basic principles of urban territorial distribution; differentiation of business environment and cities' involvement in international economic relations.

So why cities of Russia don't effectively play their major global and post-industrial functions - spread of innovations, connection to the multinational production and distribution structures, stimulating of economic development of the country, generation and commercialization of new knowledge, attracting of highly skilled labor and foreign capital.

In such difficult conditions some progress in implementing of municipal economic competencies (for example, transition to entrepreneurial principles of city management, growth of investment in reputation and image of the city) and also in organization and structure of the urban economy (development of foreign economic relations, partnerships, increasing of additional resources for cities development, improving of the cities competitiveness and investment attractiveness) is significant [15].

As internal factors of Russian urban economy development in the long term we can consider:

- decreasing of economic importance of the cities that are not involved in international relations;

- disparity in wages in industry and service;

- deindustrialization;

- international migration;

- deterioration of the environment;

- increasing of the share of pensioners in urban population;

- possibility of urban and natural environment destroying in aggressive real property market policy;

- destabilization of urban society as a result of growing importance of cultural and social capital crisis.

As factors determining urban development of Russia we may consider:

- situation on world commodity markets, that determines a potential of the federal government to implement national programs for urban development;

- unconditional increasing of importance of municipal economic regulation that directly determines a quality of urban business environment and cities competitiveness in global economy.

The most obvious tools to stimulate an economic growth of cities, enforceable at the municipal level, are:

- support of changes that can be not only economic but also institutional or organizational by origin;

- formation of unified information space serving any forms of inter-city exchanges;

- joint usage and maintenance of expensive and unique infrastructure, rationalization of necessary infrastructure costs and existing system of health and social welfare in accordance with structure and real needs of local population;

- sustaining and building of capital diversity;

- mobilizing efforts to solve common environmental problems;

- rejection of authoritarian management approaches in favor of cooperation and more flexible decision-making system based on the interests of different groups.

Taking in account trends of Russian economic system modernization, based on the presence of two dynamic factors for urban development (population mobility in its wider sense and quality of urban management systems and business environment) we proposed four possible scenarios for urban economic systems development: city in conditions of 
strong public authorities, city in terms of public- private partnership, city in extreme liberalization of business activities and developed city with a stable trend of democratic self-governance.

Probability of scenarios for urban development of Russia will depend on effectiveness of consolidation of municipal government, business and society in overcoming inertia and social development in the context of economic recession or low economic growth.

Development of Russia urban system by optimistic scenario requires a set of measures that were classified in this study into three groups:

Effective entry of largest Russian megacities into the global cities network requires an integration of corporate interests and interests of the urban community on materialistic basis (big benefits from the partnership); redistribution of internal (to the detriment of Russia finance' concentration in Moscow) and international (elimination of monopoly of Moscow as an international financial center in Russia) financial flows.

Important elements for Russian regional centers development are improvement of economic environment, increasing of budgeting efficiency, improving the work of housing and communal services, social and cultural costs optimization. Non-financial instruments for regional cities development includes improving the quality and accessibility of public services, improvement of the transport infrastructure, provision of land and real estate, creating a centers to support small and medium-sized businesses and favorable image of the city.

Strategic directions for development of small and medium-sized cities are enhancing of their role as centers of gravitating areas, including agricultural, recreational, timber; strengthening their role as structural centers in major metropolitan areas of cities; development of functions, based on existing potential of the city (especially skilled personnel).

The process of development of the Russian urban system is irreversible and logical they will seek an own "ideal" model allowing the most effective further development to ensure cities progress and entering in the national production and distribution system.

\section{References}

1. I. Starodubrovskaya, Researches of Institute of transitive economy 87, 19-24 (2004)

2. L. Berg, E. van der Braun, Urban Studies 36(5-6), 98-116 (1999)

3. P. Taylor, GaWC Research Bulletin 144, 72-76 (2004)

4. J. Logan, M. Harvey, Urban Fortunes: The Political Economy of Place (University of California Press, 2007)

5. I. Bramezza, The competitiveness of the European city and the role of urban management in improving the city's performance (Tinbergen Institute, Rotterdam, 1996)

6. H. Duffy, Competitive Cities: Succeeding in the Global Economy (Spon, London, 1995)

7. P. Hall, The World Cities (London, 1966)

8. A. Belonogov, Cities - actors of global policy? http://www.dip.pu.ru/download/belonogov548.doc

9. A. King, Global Cities: Post-Imperialism and the Internationalization of London (London, 1990)

10. O. Vendina, Urban herald 2, 205-227 (2006) 
11. J. Feagin, M. Smith, Cities and the New International Divisions of Location: An Overview. The Capitalist City: Global Restructuring and Community Politics (Oxford, 1987)

12. V. Glazychev, Political economy of the city (Delo, Moscow, 2009)

13. V. Zanadvorov, A. Zanadvorova, Economy of the city (Academkniga, Moscow, 2003)

14. L. Velikhov, Basics of urban economy (Nauka, Moscow, 1996)

15. D. Heenan, Harvard Business Review 55, 21-29 (1977) 